\title{
Governance of Cross-Border Migration in Asia
}

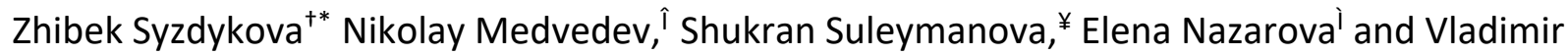
Volokhi

\section{Abstract}

An inter-ethnic migration issue has arisen due to contradictory tendencies. The relevance of the topic lies in the study and analysis of tendencies in terms of the movement of the workforce in Southeast Asia. In several Asian countries where there is a labour surplus, the migration has become one of the largest sources of income. This study examines the basic tendencies of the labour movement in the countries of Southeast Asia. The statistical data as regards the number of labour migrations for 2015-2017 have been analysed; alongside the drivers of labour migration have been identified. The main reasons for the migration are labour productivity, differences in revenues, rapidly growing number of young workers, the ageing population in other countries, reduced transport and communication costs in East and Southeast Asia. All these indicators undoubtedly have made a significant contribution to the development of migration processes. There are signs, which continually demonstrate that dependence on foreign labour has become a specific feature of some of the rich countries in the East and Southeast Asia.

Keywords: Global Economic Growth; Transnational Social Space; Inter-ethnic migration; Global Migration Issues; Migration Policy; Migration Potential

\footnotetext{
${ }^{\dagger}$ Lomonosov Moscow State University, Institute of Asian and African Studies, Russian Federation ${ }^{*}$ Corresponding Author,'Email: syzdykova_zhibek@rambler.ru

ÎPeoples' Friendship University of Russia (RUDN University), Russian Federation, Email: medvedev_rudn@mail.ru

* Institute of Public Service and Management (IGSU) Russian Academy of National Economy and Public Service under the President of the Russian (RANEPA), Russian Federation, Email: sher2016@yandex.ru

'ंFederal State Autonomous Institution of Higher education, Moscow State Institute of International Relations (University) of the Ministry of Foreign Affairs Russian Federation, Email: helena nazarova@mail.ru

'State University of Management, Russian Federation, Email: v.volokh@yandex.ru

(C) 2020 Syzdykova et al. This is an Open Access article distributed under the terms of the Creative Commons Attribution License (http://creativecommons.org/licenses/by/2.0), which permits unrestricted use, distribution, and reproduction in any medium, provided the original work is properly cited.
} 


\section{Introduction}

Today there are 232 million migrants in the world (compared to 151 million in 2005). At current rates of population migration in the world, by 2050 there will be 405 million international migrants who will develop the economy (Asian Development Bank and Mondato, 2017; The Future is Here - Project Ubin, 2017). As a result of the new dynamics of global policy and economics, the technological revolution, as a consequence of ever-increasing demographic inconsistencies, alongside the impacts of environmental changes over the next decades, international migration will change in scale, expand in its speed and complexity. The social system has lost its cohesiveness due to mass migration to the country of residents from other localities, as well as transferring distinctive cultural patterns and types of behaviour on growing scales (The Future is Here - Project Ubin, 2017).

The years 2025 and 2050 are projected to see a population peak in Yemen, Afghanistan, Saudi Arabia, Pakistan, Jordan, Iraq, Cambodia, and in a number of other countries (Asian Development Bank, 2012; Ahsan et al., 2014).

As a result of increased migration, the social tension is likely to be further intensified. In the most deprived regions, it is estimated that by 2020 , the population will consist mainly of young individuals (Jussupov, Bozhkarauly \& Rustembekova, 2018). According to the estimates, the proportion of people under the age of 30 will reach $47 \%$ in Asia; $57 \%$ in the Middle East and North Africa; and $70 \%$ in the sub-Saharan region. The significant misalignment in the Middle East and North Africa will constitute a particular threat to the European Union by geographic proximity. In the poorest and often most unstable countries of the world, it is presumed that by 2020 , young people will represent the largest share of the population. Most of these countries are without economic, institutional and political resources for the successful integration of young people into the society (Ahsan et al., 2014; De, 2017).
In addition, the world poverty is increasingly concentrated in chaotically growing urban megalopolises, which are vulnerable to the impact of political extremists and religious fundamentalists, whose appeals are further reinforced by xenophobic attitudes (Ratha, 2013; Migration News, 2014; Gohain, 2017; Begichev, Galushkin, Zvonarev, \& Shestak, 2019).

The assimilation supposes not only formal acceptance of citizenship and loyalty towards a certain common future but also sincere acceptance of a common past, often mythological (Rallu \& Ined, 2008). Accordingly, a solution must be sought not so much in the field of inter-ethnic relations, as in the social interaction of various sectors of society (Asian Development Bank, 2012).

It should be noted that migrants transform the social, economic, managerial institutions of the host country, thereby creating a "diversity capital". That is, the capacity of the social system to open, incorporate many new groups, in particular immigrants, is the key to the sustainable development of the country within globalisation and is an extremely valuable innovative resource (Statistics and Databases, 2017). The appearance of the latter is caused by "transnationalism". The formation of transnationalism is related to multidirectional and diverse international mobility. In this case, the social space is not divided by state borders and in which strong social ties connect people formally belonging to different social layers (The Future is Here - Project Ubin, 2017). In the previous period, the migration was associated with relocation for permanent residence. However, nowadays, the crucial changes in transport and communications have made it possible to work in one country and have a home, a family - in another (that is, allowing one to make constant movements between them). Even in the case of relocation abroad for permanent residence, modern communications enable migrants to maintain close and continuous contact with their relatives (Kaur, 2010). As a result, more and more people who 
are physically located in one country identify themselves with another or equally refer to both, and even to a large number of states. On the one hand, the transnational space is a product of mass international migration, and on the other, it has the opposite effect on migration's volume and features. In this context, the disparity between origin country and target country is being virtually shortened, as the technical options, expenditure reduction in transport, and communication services allow migrants to regularly contact, and more often visit their families (Development Asia, 2016).

In the process of social space transnationalisation, the remittances of migrants are of great importance (Development Asia, 2016). The remittances positively impact economic development: they ensure profitable investments that (even if spent on consumption purposes) stimulate production due to the multiplier effect. Based on the estimate for every dollar of the remittances, there is an increase in domestic production at the value of $2 \$$ (Ahsan et al., 2014; Development Asia, 2016). In the scientific literature, this is determined by the formula of five "T", including transfers, transport, tourism, telecommunications, and trade. That is, the demand for migrants accelerates the development of areas, and thus the entire economy develops as well (Statistics and databases, 2017).

This study is aimed at examining the basic tendencies of labour movement in the countries of Southeast Asia. To achieve it, it is necessary to probe the following:

- The drivers of the migration.

- Approaches to the management of labour migration in the countries of Southeast Asia.

- Tendencies and perspectives for the labour movement in the region.

The study consists of six sections. In the introduction section, we have shared theoretical information and stated the objectives of the study. The next section is dedicated to Literature Review; this section reviews other studies on the topic and addresses the gap. The methods section describes the methods of research. After that, there is the results section which explains the results of the study and discussion where other articles on the topic are being discussed. The last section presents the conclusion and summarises the study. The following section reviews relevant literature.

\section{Literature Review}

Ravenstein (1885) was one of the first scholars to describe the phenomenon of migratory flows' activation. Migratory flows in the 19th century were however not so much associated with the search for a better life (for example, when someone is looking for employment as a housekeeper to achieve higher wages), but with the industrialisation of cities. Among the prevalent migration causes, there was also the emergence of professions that are not dependent on gender stereotypes, and the opportunity for women to engage in a "nonfemale" profession (for example, working at the manufactory) (Ravenstein, 1885). There are historical cyclicity and repetition of migration processes with a difference of one and a half centuries. However, there might be an increase in migration due to the intensification of globalisation processes and envrinmental crises. In this context, Mottaleb, Krupnik, Keil, \& Erenstein (2019) state that in developing countries, rural areas are currently experiencing an environmental crisis, which increasingly causes cross-border migration of population. For example, the rural areas of South Asia has faced with this phenomenon. In the Indo-Bangladesh context, the migration trend is generating a range of destabilising tensions in India-ranging from socio-political, economic, and ethnic and to communal. The study suggests that this flow of population will continue at a pace that is even greater until the native courtiers of the migrants take actions (Mottaleb et al., 2019). In a similar context, Ihara (2019) has researched international labour migration in Asia, a country where intense migration has been recorded over the last four decades.

There is, however, the extensive literature on the subject of marriage migration (Choi \& Tienda, 2017; Sun, 2017). There are a few recurring themes in response to the complexity 
of such a process: the global flow of capital, governmentality, the role of women, the power geometry, cultural identity and diaspora. In recent years, scholarly work on migration has started to employ theories of effect to understand the complexity of the migratory process. The multi-faceted and varying incentives for cross-boundary mobility, such as different liaisons and attachments, are no longer in the focus of the mainstream migration research paradigms (Mai \& King, 2009). In her study (2013), Anne-Marie D'Aoust explored what engagement with emotions such as love does to governmentality in the process of marriage migration. Thus, "technologies of love involve a close examination of the various combinations that encompass subject, body, territory, spatiality, language, artefacts, modes of knowledge, and institutions" and "play a significant role in the governmentality of marriage migration in connecting intimacy with citizenship in ways that go beyond what we might conceive of as the rationalization of an emotional realm" (D'Aoust, 2013: 274).

A recent study by Lionel Cottier (2018) unravels about international retirement migration, which is a relatively new phenomenon in Asia. It is linked to the growth of elderly Japanese mobility. However, the national borders are less penetrable in this sense. This is despite contributions made by government to promote the movement of pensionable-aged people (Toyota, Böcker, \& Guild, 2006). Earlier, in 2009, Sills studied the regional responses to migrant labour issues. The author explains that there has been a "reluctance to discuss labour migration issues as cross-border or regional phenomena" (Sills, 2009: 220), resulting in a disjointed and haphazard application of international labour codes and human rights treaties.

The available literature on migration and health in Asia knows several cases when migration helps improve the health of a travelling person. However, many cases are evidence of adverse effects (e.g. the cross-border HIV/AIDS transmission) and increasing health-care 'burdens' in the sending communities (Tang \& Chen, 2018). Indeed, there is evidence to suggest that there are more women among migrants than men. Although women may be associated with domestic life, a significant proportion of women tend to move from the rural area to manufacturing cities, and the percentage happens to be higher compared to domestic service chasers (Resource, 2016).Linked to this, one can argue that in many Asian countries, there are more female migrants than male migrants, as stated by the ILO (Statistics and databases, 2017). The latter may provoke social crises in some families and social strata of the cultures with masculine values (where social roles are gender-separated). These social crises make households more vulnerable to changes. .

One of the problems of today's global migration analysis is the reliance on one source of information (or one method of collecting information, for example, a population census). There are no uniform standards regarding the use of definitions. These problems have existed for a long time; Tobler (1995) described them in detail. However, with the intensification of information flows and ease of access to information, these problems only deepen. When it comes to definitions, it is common that they are used incorrectly in everyday life as well. Whereas, the quality of migration studies may reduce if such studies are not cross-disciplinary and rely on data from only one international agency. This perspective illustrates the governance of cross border migration in Asia. The following section discusses the methods deployed for this study.

\section{Methods}

The UN reports on migration serve as a basis for the study (Documents, 2017). Alongside, this study also uses the following data sourcesUNCTAD (Statistics, 2017), International Labour Organisation (ILO) (Statistics and databases, 2017), and ASEAN (ASEAN Publications, 2020). Using these reliable sources, the research focus was narrowed to the following indicators:

- The number of migrants from Asia for 2015-2017.

- The number of labour migrants from East and Southeast Asia 2015-2017. 
- The percentage of representatives of migrants' communities in accordance with the various drivers of migration.

When collecting information, a problem was encountered with the record of illegal residents of Asian countries (Shestak \& Volevodz, 2019). Hence, the study has a limitation in terms of assessing the situation of migrants in Asia exclusively de jure, which may differ from the de facto situation.

We synthesised qualitative data of demographic reports of the Asian countries and analysed the reporting of international organisations. Aspects of the socio-economic development in the region were differentiated and quantitative data were determined for the analysis.

For the primary processing of quantitative data, we used the STATISTICA programme. Its use made it possible to unify data from reports of international organisations to a system of common indicators. Based on the latter, the qualitative results were obtained and conclusions of the study were formulated.

Using the deduction method, the authors processed analytical data on the international regulation of migration, which allowed determining particular results in the existing legal framework of certain countries.

By induction, we were able to identify a single tendency of "reproductive migration" based on scattered data on precedents in countries of Western Europe, China and India. To determine the conceptual foundations of the study, we used theoretical abstraction from the popular concepts of the "demographic transition" by Frank Notestein and the theory of cultural dimensions by Geert Hofstede. The following section discusses the results.

\section{Results}

\section{Labour Migration Drivers in Southeast Asia}

There have been globalisation processes and economic and social transformations for over 30 years over the East and Southeast Asia. These processes have triggered active cross-border labour migration. The unsteady growth of the region's economies has led to a more uneven distribution of relative incomes and living standards. The main reasons for the migration, such as labour productivity, differences in revenues, a rapidly growing number of young workers, the ageing population in other countries, reduced transport and communication costs are present in East and Southeast Asia and undoubtedly made a significant contribution to the development of migration processes. As an example, the average earnings in the construction and manufacturing sectors in Japan, the Republic of Korea, China are significantly higher than in Indonesia, Thailand and the Philippines (Zhuang, Edwards, \& Capulong, 2001). Short-term changes in the migration movement have contributed to the growth and decline in demand for labour. The extension of migration flows is associated with infrastructure investments (for example, the construction of the subway in Singapore or the construction of airports in Hong Kong, China) and the "boom" in real estate (Glaeser, Huang, \& Shleifer, 2017). The decay in migration flows was caused by the fight against illegal migration and the subsequent, albeit temporary, restrictions on immigration (Rallu \& Ined, 2008).

Unemployment rates in the countries to where migrants have moved were not such decisive factors as, for example, the effect of per capita income growth or a decline in education. The proportion of foreign workers in agriculture, fishery and construction rose (Mottaleb et al., 2019). Local workers leave these jobs as soon as better prospects appear in more modern areas (Mottaleb et al., 2019). The same refers to small enterprises. For instance, the Small Business Union in the Republic of Korea has successfully lobbied for hiring low-skilled workers as interns, despite government policies to accept only specialists and skilled workers (Zhuang, Edwards, \& Capulong, 2001). The vocational training programmes continued for many years, but the authorities were forced to abandon them in favour of a "guest workers programme" because of criticism of the violation of workers' rights (Akimzhanova et al., 2018).

There are signs, which have continually demonstrated, that dependence on foreign 
labour has become a specific feature of some of the richer countries in East and Southeast Asia.

\section{Approaches to the Management of Labour Migration in Southeast Asian Countries}

Notwithstanding, essential differences in the development of the countries of Southeast Asia, the strategies of labour migration management in the region have common features. If it refers to host countries (labour recipient countries), the features are the following:

- Unilateral management of the labour force.

- Employment policy under the guidance of employers.

- Temporary employment of labour migrants only as "guest workers" or "interns".

- Refusal to migrant workers in long-term benefits.

- The use of a periodic amnesty to solve the illegal migration issue.

The one-sided management of labour migration is manifested quite clearly, unlike in Europe. In East and Southeast Asia, there are very few examples of bilateral labour migration agreements between countries of origin of migrants and target countries. Despite pressure from countries of origin, in most target countries, they managed to avoid their specific employment obligations and to treat migrant workers adequately. This limits the role that labour donor states play in the recruitment and employment processes of their workers abroad, with the exception of China and Vietnam, where licenses for hiring are common in many stateowned enterprises. This situation has led to widespread commercialisation of migration processes with all respective benefits and risks. Benefits usually preview the efficiency of private hiring that causes rapid growth of the system. Risks associated with high fraud, high cost of mediation for hiring, which could be minimised through cooperation between donor countries and recipient countries.

For the employment of workers, the following is necessary:
- Prior permission of the authorised bodies of respective countries.

- Submission by one of the countries of the list of available jobs and the other one a list of applicants for these jobs.

- Control by both parties to ensure that the work permits and appropriate visas are issued, that employees comply with health insurance requirements, that savings are made, taxes are paid, and labour agreements are signed.

Unfortunately, this system is inefficient because the costs of implementing collectively established procedures significantly exceed the costs on the non-registered system that the authorities tried to replace. Recent studies show that this policy has remained ineffective so far.

\section{Discussion}

Temporary employment schemes for migrant workers suggest that the majority of countries that allow immigration, such as Korea, Singapore, Malaysia, and Brunei Darussalam have adopted either "guest workers" or "interns" programmes. These programmes are grounded on the idea of employment without providing unskilled foreign workers with an opportunity to get the right to work on a permanent basis (Migration News, 2014). Employment of low-skilled foreign workers usually provides for a renewable work permit for one year (Statistics and databases, 2017). The migration is deemed as a means of overcoming a temporary shortage in the labour market, which may or may not be used depending on economic conditions. From this point of view, it may seem that the system works well to meet the working needs during the upswing in sectors such as agriculture or construction. However, this approach has encountered issues when jobs are not "time-limited" compared to regular work in a factory or the provision of the services on a regular basis. Such a policy contradicts the interests of employers and migrant workers in continuing relationships. Considering the issue, countries should share various strategies to prevent unskilled foreign workers from settling. These strategies prevent the exclusion of temporary migrants in the field of social security, 
referring workers to specific employers for their work visas, restricting their movement (Ratha, 2013).

The temporary work makes it challenging to qualify for retirement pensions for most labour migrants. Laws in most countries are also excluded from the scope of receiving pensions, even if the required number of working years is reached (Veresha, 2016). Migrants, who have spent a large part of their working life in foreign countries, have been in an unfavourable position unless their own governments create special programmes in their social security systems to serve citizens working abroad (Development Asia, 2016; De, 2017; The Future is Here - Project Ubin, 2017). Such a situation is possible to mitigate through implementing necessary measures that would allow short-term migrants to accumulate pension rights. In the framework of two-party or multilateral agreements, countries, where migrants were recruited and made their contribution to the development of the economy, can agree on the formula for distributing the payment of his or her pension. However, it will cause mandatory amendments to social security laws (Development Asia, 2016).

Asian migrant donor governments have developed approaches to migration management that reflect, on the one hand, their desire to provide their people with better employment opportunities and higher incomes, and on the other hand, the desire to protect the rights and the interests of their citizens abroad. These approaches contain various activities, among which it is possible to single out:

- Activities aimed at the extension of labour employment opportunities.

- Hiring rules and establishing labour agreements within a minimum standard.

- Insurance of labour migrants against various unpredictable circumstances.

- Assistance to employees abroad (especially through the labour attaché).

The migration for the sake of employment is now considered by almost all national governments as an increasing phenomenon, a feature of the globalisation process and largely as a positive development, which contributes not only to investment in education but also to trading opportunities. More and more governments are regarding labour migration as part of their employment strategy and are carrying out appropriate measures to take advantage of all available challenges in this area (Asian Development Bank, 2012).

There are specific migration law instruments and regulatory approaches. Since the majority of the workers travel to countries where there are deficiencies in the protection of rights of the migrant workers (in law or practice), the authorities have focused on employment contracts as a legal basis for approving and protecting the rights and duties of their citizens. That is why the special attention was paid to job fraud, misinformation and contract substitution, and governments focused on appropriate policies and measures to stop it. The commercialisation of migration processes, especially when hiring, is another major issue for donor countries. The administrative authorities, some of which do not have proper legal mandates and adequate budgetary resources, should perform the verification of the faithful fulfilment of obligations by foreign employers, check the validity and adequacy of the proposed employment, registration of contracts providing for punishment for unlawful actions, ensure prosecution of workers without a license and solving disputes between employees and intermediaries (Rallu \& Ined, 2008).

\section{Conclusion}

The key aim of this study was to examine the tendencies of the labour migration in the countries of Southeast Asia.

The findings of the study unravelled that employment policies implemented by employers feature that in East and Southeast Asia, the recruitment of foreign workers is rarely determined by law using quotas, and is usually managed by employers. In this case, Japan is the only country where immigration laws in force strictly prohibit attracting low-skilled foreign labour, even if labour migration, as before, is determined by the employer. The employment policy managed by employers means diminishing the impact of countries within 
migration management and can easily lead to prolonged or even increased dependence on foreign workers. Reforming this area is becoming more difficult because economic interests exist to maintain the status quo.

According to our analysis, the transnational social space means certain factors, such as:

The emergence of foreign diasporas, which are closely associated with numerous ties with their nations. Historically, India and China have considered their diasporas as reminders of colonial days. However, now these nations recognise that overseas communities can provide an important lobby for advancing their interests on the political scene (Cohen, 2019).

The local concentration of an increasing number of people of different ethnonational identities.

The interpenetration of cultures due to the global dissemination of information through the world media.

The prevalence in the international business of transnational corporations with the formation of an increasing stratum of their employees, specialists and managers, whose career is connected with many countries of the world.

The globalisation of finance in the form of remittances of migrants to their homeland, whose importance as a source of income for developing countries is constantly growing.

Strengthening transnational political activity of non-governmental and international organisations as influential factors of civil society.

The ability to work, regardless of physical residence, the virtual presence of a person or institution due to the Internet, mobile communications, satellite television, etc.

The general approach to solving this issue is to declare an amnesty in order to encourage registration of temporary migrants. However, in the contemporary environment, it should be solved taking into account many aspects, such as:

- Relocation of low-skilled local employees.
- The protection of asylum seekers

- Labour costs of the production and export of labour-intensive products.

- Care for national security.

- Friendly relations with neighbouring states.

- Consideration of human rights.

- Training migrant children.

Countries, from which migrants come, should also develop appropriate measures in case of unforeseen circumstances, such as denial of employment and forced return of workers; legal protection of citizens involved in expensive lawsuits in host countries; medical care for injured workers, who were abandoned by their own employers; resolving conflicts and disputes with employers.

\section{References}

Ahsan, A., Abella, M., Beath, A., Huang, Y., Luthria, M., \& Van Nguyen, T. (2014). International migration and development in East Asia and the Pacific. The World Bank.

Akimzhanova, M., Ilyassova, G., Nukusheva, A., \& Rustembekova, D. (2018). Extending Legislation of the Republic of Kazakhstan by Anchoring International Child Rights. Journal of Legal, Ethical and Regulatory Issues, 21(3), $17 \mathrm{p}$.

ASEAN Publications (2020). Retrieved on 13 January 2020 from, https://asean.org/resources_cat/aseanpublications-3/

Asian Development Bank (2012). Global Crisis, Remittances, and Poverty in Asia. Manila. Retrieved on 27 April 2019 from, https://www.adb.org/

Asian Development Bank and Mondato (2017). Financial Disruption and Inclusion: Digital Payments Systems, Mobile Money Services, and Agent Banking. Manila. Retrieved on 03 June 2019 from, https://www.adb.org/

Begichev, A. V., Galushkin, A. A., Zvonarev, A. A., \& Shestak, V. A. (2019). History of the creation and activities of the League of 
Nations. Voprosy Istorii, 9, 108-113. https://doi.org/10.31166/Voprosylstorii2 01909Statyi04 (In Russian)

Choi, K. H., \& Tienda, M. (2017). Boundary crossing in first marriage and remarriage. Social Sience Research, 62, 305-316. https://doi.org/10.1016/j.ssresearch.2016 .08 .014

Cohen, R. (2019). Diasporas: changing meanings and limits of the concept. The Handbook of Diasporas, Media, and Culture, 21-30.

Cottier, L. (2018). Culture, financial constraints, and retirement decision. Labour Economics, 53, 128-145. https://doi.org/10.1016/j.labeco.2018.04. 008

D'Aoust, A. (2013). In the name of love: Marriage migration, governmentality, and technologies of love. International Political Sociology, 7, 258-274. https://doi.org/10.1111/ips.12022

De, S. (2017). Economic Properties of Remittances. Migration and Remittances for Development in Asia (Draft). Asian Development Bank.

Development Asia (2016). Case Study: A 'SMART Money' Solution for South Asia. Retrieved on 12 May 2019 from, http://development.asia/casestudy/smart-money-solution-south-asia

Documents. United Nation (2017). Retrieved on 12 June 2019 from, https://www.un.org/en/sections/general/ documents/

Glaeser, E., Huang, W., Ma, Y., \& Shleifer, A. (2017). A real estate boom with Chinese characteristics. Journal of Economic Perspectives, 31(1), 93-116.

Gohain, M. P. (2017). 60 Percent of Engineering Graduates Unemployed. Economic Times. Retrieved on 14 September 2019 from, https://timesofindia.indiatimes.com/hom e/education/news/60-of-engineeringgraduatesunemployed/articleshow/57698133.cms
Ihara, R. (2019). Heterogeneous labor and agglomeration over generations. Regional Science and Urban Economics, 77, 367-

381.

https://doi.org/10.1016/j.regsciurbeco.20 19.06.003

Jussupov, M., Bozhkarauly, A., \& Rustembekova, D. (2018). Formation and Development of State Migration Policy. Journal of Advanced Research in Law and Economics, 9(5 (35)), 1643-1652. https://doi.org/10.14505/jarle.v9.5(35).1 6

Kaur, A. (2010). Labour migration trends and policy challenges in Southeast Asia. Policy and Society, 29(4), 385-397. https://doi.org/10.1016/j.polsoc.2010.09. 001

Mai, N., \& King, R. (2009). Love, Sexuality and Migration: Mapping the Issue(s). Mobilities, 4(3), 295-307. https://doi.org/10.1080/17450100903195 318

Migration News (2014). Southeast Asia, 21(4). Retrieved on 11 July 2019 from, https://migration.ucdavis.edu/mn/

Mottaleb, K. A., Krupnik, T. J., Keil, A., \& Erenstein, O. (2019). Understanding clients, providers and the institutional dimensions of irrigation services in developing countries: A study of water markets in Bangladesh. Agricultural Water Management, 222, 242-253. https://doi.org/10.1016/j.agwat.2019.05. 038

Rallu, J. L., \& Ined, P. (2008). Population, Migration and development in Asia, with special emphasis on the South Pacific: The Impact of Migration on population and the MDGS. Retrieved on 29 June from, http://www.un.org

Ratha, D. (2013). The impact of remittances on economic growth and poverty reduction. Policy Brief, 8(1), 1-13.

Ravenstein, E. G. (1885). The laws of migration. Journal of the statistical society of London, 
48(2), 167-235.

https://doi.org/10.2307/2979181

Shestak, V. A., \& Volevodz, A. G. (2019).

Modern requirements of the legal support of artificial intelligence: a view from

Russia. Russian Journal of

Criminology, 13(2), 197-206. (in Russian).

Sills, S. J. (2009). Transnational Migration and Work in Asia. Kevin Hewison and Ken Young, eds. Eurasian Geography and Economics, 50(5), 617-619. https://doi.org/10.2747/15397216.50.5.617

Statistics and databases. International Labour Organization (2017). Retrieved on 23 May 2019 from, https://www.ilo.org/global/statistics-anddatabases/lang--en/index.htm

Statistics. United Nation Conference on Trade and development (2017). Retrieved on 13 May 2019 from, https://unctad.org/en/Pages/statistics.as px\#

Sun, J. (2017). Marriage migration in Asia: Emerging minorities at the frontiers of nation-state. Asian Journal of Women's Studies, 23(2), 269-271. https://doi.org/10.1080/12259276.2017.1 317905

Tang, K., \& Chen, W. T. (2018). HIV and religion in HIV-infected Asians and their families:
A qualitative study. Applied Nursing

Research, 44, 18-24.

https://doi.org/10.1016/j.apnr.2018.09.0 03

The Future is Here - Project Ubin. SGD on Distributed Ledger (2017). Deloitte and the Monetary Authority of Singapore. Retrieved on 22 December 2019 from, https://www2.deloitte.com/content/dam /Deloitte/sg/Documents/financialservices/sg-fsi-project-ubin-report.pdf

Tobler, W. (1995). Migration: Ravenstein, thornthwaite, and beyond. Urban Geography, 16(4), 327-343. https://doi.org/10.2747/02723638.16.4.327

Toyota, M., Böcker, A., \& Guild, E. (2006). Pensioners on the Move: Social Security and Trans-border Retirement Migration in Asia and Europe. IIAS Newsletter, 40 (Spring), 30.

Veresha, R. V. (2016). Determination Motive through the Prism of the General Concept of the Motives of Human Behaviour. International Journal of Environmental and Science Education, 11(11), 4739-4750.

Zhuang, J., Edwards, D., \& Capulong, M. V. A. (2001). Corporate Governance \& Finance in East Asia: A Study of Indonesia, Republic of Korea, Malaysia, Philippines and Thailand. Asian Development Bank. 